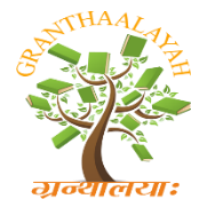

INTERNATIONAL JOURNAL OF RESEARCH GRANTHAALAYAH A knowledge Repository

Social

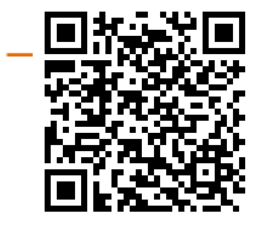

\title{
SCHOOL-BASED TEACHER DEVELOPMENT PROGRAMS IN SECONDARY SCHOOLS IN SRI LANKA
}

\author{
Dr. Senevirathna Bandara *1 \\ ${ }^{* 1}$ Department of Humanities, Faculty of Social Sciences and Humanities, Rajarata University of \\ Sri Lanka, Mihintale, Sri Lanka
}

\begin{abstract}
Teacher professional development is the 'key' of the developing students' quality of the outcomes in the 21st century. Under such a situation, teachers have to update and intensify their knowledge, skills, attitudes and practices according to students' current expansive demand. In this context, School-Based Teacher Professional Development is a very important concept, because it allows teachers to plan, organise and implement their own professional development programs, considering their particular needs, as well as those of students and school. However, this concept has not been extensively developed in the Sri Lankan education context. Focusing on the Sri Lankan secondary school context, this study examines the possibilities, effectiveness, strategies, issues and challenges involved in implementing these programs in the teachers' professional development. Simultaneously, the situation of the Non-School-Based Teacher Development programs are also examined because these are currently prominent and this study assumed that both programs need to be integrated in order to provide balanced teacher professional development. The qualitative research approach and the case-study method has been employed. The data were collected by conducting interviews, non-participative observation and sample-based documentary searching. According to the findings, strong recommendations were proposed and relevant guidelines were suggested for future researches.
\end{abstract}

Keywords: Teacher Professional Development; School Context; Qualitative Research Approach.

Cite This Article: Dr. Senevirathna Bandara. (2018). "SCHOOL-BASED TEACHER DEVELOPMENT PROGRAMS IN SECONDARY SCHOOLS IN SRI LANKA.” International Journal of Research - Granthaalayah, 6(5), 190-200. 10.29121/granthaalayah.v6.i5.2018.1440.

\section{Introduction}

The Ministry of Education in Sri Lanka has recognised that good teachers are 'keys' to enhance the quality of education (MOE, 2004). Furthermore, MOE (2005) states that Sri Lanka has already considered professional development for teachers as an essential part of the education system because professional development enhances the quality of good teaching (DETYA, 2005; Sethunga, 2007). In addition, the University of Western Sydney emphasises the importance of the relationship between quality teaching and student outcomes (Zammit et al., 2007). 
Recent research findings show that there is a strong relationship between teachers' teaching quality and students' learning outcomes. The quality of classroom learning is strongly determined by the improved quality of student achievement and is important than other socio-economic factors (AISV, 2006). The impact of classroom practice is depicted in the figure below.

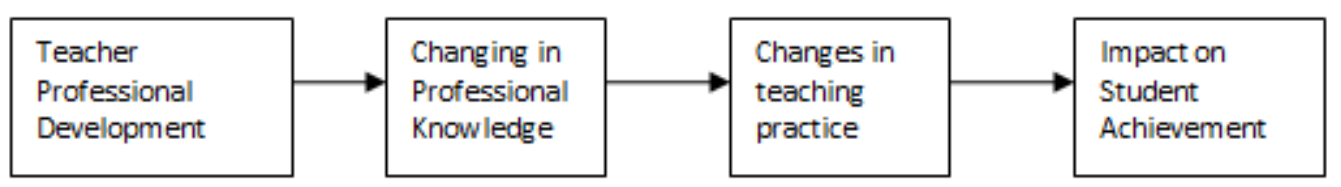

(AISV, 2006)

Figure 1: Teacher PD and impact on students' outcomes

The National Science Education Standards (2008) believes that, “...effective professional development programs becomes central in teachers' lives" (NSES, 2008, p.1), and Hayman (2009) pointed out that well organised professional development programs can enhance teachers' skills, knowledge and attitudes. In addition, Linda (2005, p. 238) states "... research has shown that many of schools have improved teaching practices and student achievement, while building professional knowledge" this statement is based on research which was conducted in the United States.

Professional development programs for teachers in Sri Lanka are divided into two groups. The first is the School-Based Teacher Development (SBTD) - These programs are considered an effective strategy for teacher professional development because they are designed, organised, implemented, owned and controlled by principals and teachers of the schools (Monyatsi, 2006; Margarita, 1997; Clair \& Adger, 1999; Good et al., 2003; Wickramasinghe, 2002; Blackmore, 2000).

The second is the Non School-Based Teacher Development (NSBTD) program, NSBTD programs (Government or non-Government). These programs are organised and implemented by external organisations or institutes of the schools, such as Zonal Education Offices, Provincial Ministry of Education, the Ministry of Education, the National Institute of Education as well as various NonGovernment Organisations. These Non-School-Based Teacher Development (NSBTD) programs are held for school teachers who come from various schools which are situated in different geographical areas. As a result, these teacher development programs may create ineffectiveness in teacher professional development since they are planned without considering the needs of individual schools and the willingness of individual teachers. One of the significant issues for teachers is that they have to travel long distances from their workplaces to participate in these professional development programs.

These two types of professional development programs help to develop teachers' knowledge, skills, competencies and attitudes. They also have particular advantages and disadvantages. This study focuses on investigating School-Based Teacher Development (SBTD) programs in the secondary education system of Sri Lanka, because they are currently rarely used in Sri Lanka. In addition, these programs consider the teachers' needs and current available resources. Therefore, School-Based Teacher Development (SBTD) programs are popular and beneficial to teachers in various ways in both developed and developing countries. 
In addition, Sri Lankan education researchers have realised the importance of the school-based professional development (SBTD). Sethunga (2007, p.3) states "Many international and local researchers have emphasised the need for school-based teacher professional development programs". Under such a situation, in order to organise and implement SBTD programs in secondary schools in the Sri Lankan context, the principals and staff of schools have two major options:

- The Program on School Development. In 2007, the Sri Lankan government inaugurated this program particularly aimed at school improvement and includes new directions for SBTD programs (Sethunga, 2007).

- The School Based Management (SBM). In the late 1990s the concept of SBM was established in the Sri Lankan education system (MOE, 2005). This concept gives opportunities to provide SBTD programs for teachers.

As has been mentioned above, SBTD programs are not very common in the Sri Lankan education system. However, researchers discovered that some secondary schools have organised and implemented effective and innovative (SBTD) programs using various strategies and methods. Furthermore, there is potential for these programs to be developed to improve the professional standards and required interpersonal and other skills of secondary school teachers; but the development of these programs is one of the many complicated issues within the education system in Sri Lanka. Therefore, this research inspired to investigate the current situation on School-Based Teacher Development programs in ten selected secondary schools in Sri Lanka.

School-Based Teacher Development (SBTD) programs in Sri Lanka do not have a long history and SBTD was accepted as a concept in the education system in the early 1980s as part of national education reforms (Wickramasinghe, 2002). Further, the history of SBTD programs in Sri Lanka can be traced from a Hand Book for school principals published by the Sri Lankan government. The Hand Book comprised fourteen chapters, with chapter five of the Hand Book dealing with 'Staffing and staff development'. In addition, that Hand Book for school principals' included a subject that focused on SBTD programs and its title was 'Organisation of in-school teacher training programs'. It indicated the following four sub-activities:

1) Organise a system of appointing grade/subject co-ordinators and sectional heads.

2) Plan out a program of workshops, regular faculty and group meetings, etc.

3) Provide teachers with packages of self-learning materials.

4) Organise contact sessions to solve teaching/learning problems on a person-to-person basis.

These sub-activities are policy documents to principals and this Hand Book states how to organise SBTD programs with consideration to these activities (MOE, 1996).

That means in the 1990s the Sri Lankan government took action to develop school-based teacher professional development even though, over these 30 years the development of this field is questionable in Sri Lanka.

Furthermore, considering the Sri Lankan history of SBTD programs, another aspect related to SBTD was a framework for Annual Implementation at School Level (1983-part II school development) and that document outlines several programs and projects. Some of them are 'Inservice Training of Teachers' (Internal) and 'Professional Growth of Teachers' and the aim was to develop SBTD. Thus, in the 1990s, there was a significant initiative by the Sri Lankan 
government to develop School-Based Teacher Professionalism, in conjunction to the massive National reforms in 1996 (MOE, 2004). As a new concept of SBTD programs for Sri Lanka, Sethunga (2007, p .3) explains that "even though the paradigm shift from centralised in-service programs moved towards SBTD initiatives, in the Sri Lankan context it would have to ascertain whether such modalities would be applicable or how it could be approached within the present teacher education system. In order to develop effective SBTD initiatives, rigorous research studies would have to be conducted".

After the beginning of the 21st century, improvements or major changes in the field of SBTD programs in Sri Lanka have not been prominent. However, in 2007, a new program was proposed, called 'Program on School Improvement' (PSI). In line with the objectives of the program on PSI and with the new directions in teacher professional development, the Ministry of Education (MOE) has a number of innovative activities including a pilot program on SBTD where 40 schools have been selected from eight (8) Zones representing each Province" (Sethunga \& Devananda, 2007, p. 2). Furthermore, considering the literature of teacher professional development, the Sri Lankan government has already recognised that professional development of the teachers and principals is essential, and that this program should be promoted and continuously offered (MOE, 2005).

In addition, the Sri Lankan government recognised five aims that can be achieved through schoolbased professional development. The first is facilitating teacher development programs. The second is promoting on-site teacher development programs (each school will conduct site-based programs). The next is facilitating teachers' participation in continuing teacher education programs, and finally, providing training for principals and Senior Management Teams (SMTs) on educational planning, IT usage, financial management, quality improvement and organising effective on-site teacher development programs. The last is conducting a network of monitoring mechanisms (Mathews, 2002).

In addition, a project was conducted in Sri Lanka that aimed to assess the quality of Sri Lankan secondary education for years 6-11. This project provided equitable access to quality secondary education participation in rural areas. The project had four main objectives: revision in curriculum; improvement in teacher education and training; reform in education and examination systems; and improvement in school administration and academic learning through the provision of physical infrastructure and equipment to teach Science and Computer studies in selected schools (Mathews, 2002). The project implemented teacher training programs in order to improve teacher education and professional development under improvement in teacher education and training objectives. The project objective had three aims: firstly, preparing self-study training materials for teacher trainers with special emphasis on the use of multimedia and distance teaching methodology; secondly, supporting pre-service education for student teachers, in-service training of untrained teachers and short-term refresher courses in newly specialised subject and teaching methodology; and thirdly, upgrading facilities at Teacher Training Colleges (TTCs) and Teacher Education Institutes (TEIs). However, this project did not consider developing or encouraging SBTD programs as an effective part of teacher professional development.

Further, considering the literature of SBTD programs, Dill and Stafford (2010) describe research findings from a study conducted in the United States based on school-based teacher education. They describe a SBTD program which was held in a summer. During this program some topics 
were included, such as classroom organisation, behaviour management, individualised education programs, and models of teaching were taught during the guided observation time in the summer. Further, the participant learned how to write lesson plans from master teachers with experience both in the theory of curriculum planning and in the practical design of lesson plans. In addition, the program provided lessons of motivation, positive discipline, stress management, violence prevention, and communication skills. In analysing these experiences in the report, some important aspects of SBTD programs are reflected.

\section{Materials and Methods}

This section briefly discusses selected research approach, research method, data collecting tools, the sample of the study and data collecting procedures.

\subsection{Methodology}

The overarching research question of the investigation is how do Sri Lankan secondary schools implement SBTD programs?

Four sub-research questions are made to seek answers to the overarching research question:

1) What factors affect the development of SBTD programs in Sri Lanka?

2) How is the effectiveness of the SBTD programs demonstrated in each school?

3) Which professional development activities are reflected in the SBTD programs in secondary schools in Sri Lanka?

4) What specific changes in teacher practice followed SBTD programs?

Research methodology is a broad concept comprising aspects such as design, data collection, data analysis and theorizing, as well as social, ethical and political concerns.

Qualitative research approach and Case study method used for the study. Ten secondary schools were selected (ten cases) to collect qualitative data.

Regarding the use of qualitative research methods, Ried and Petocz (2006, p. 1) mentioned that "Much mainstream research in higher education uses qualitative methods to examine learning situations..." In addition, the qualitative research method is less structured and often it is more flexible than the quantitative research design (Wiersma \& Jurs, 2005). Further, Johnson and Christensen (2000, p. 17) defines the qualitative research as, "Qualitative research is research relying primarily on the collection of the qualitative data (e.g. non-numeric data such as words and pictures)". Furthermore, Anderson (1998) categorises qualitative research method as applied, case study, ethnography, grounded theory and phenomenology. In addition, qualitative research method includes various kinds of studies (Wiersma \& Jurs, 2005; Anderson, 1998). Some of them are case studies, historical research, as well as ethnographic research (Borg et al., 1993). In addition, Merritt (2003, p. 65) lists the characteristics of qualitative research. The four characteristics of qualitative research are, "It is the study of people and things in natural settings; it interprets both things and people's lives and experiences; it uses a variety of empirical materials to provide rich, in-depth and contextualised data and it explains and understands social phenomena from the participant's perspective”. 


\subsection{Participants}

The participants for the study were ten secondary school principals who have considerable experience and qualifications, from three administrative districts selected in this study. Five were male and five were female participants. The samples of school included were girls, boys and mixed schools. Below Table 1. Shows the selected sites and the participants of this study.

Table 1: General information of the sites

\begin{tabular}{|l|l|l|l|l|l|}
\hline $\begin{array}{l}\text { School } \\
\text { Number }\end{array}$ & $\begin{array}{l}\text { School } \\
\text { type }\end{array}$ & Grades & Gender & $\begin{array}{l}\text { Number of student } \\
\text { groups }\end{array}$ & $\begin{array}{l}\text { Number of Teacher } \\
\text { groups }\end{array}$ \\
\hline No. 1 & 1 AB & $6-13$ & Mixed & $1-2000$ & $1-100$ \\
\hline No. 2 & National & $1-13$ & Girls & $1-5000$ & $1-200$ \\
\hline No. 3 & 1 C & $1-13$ & Mixed & $1-1000$ & $1-100$ \\
\hline No. 4 & National & $1-13$ & Girls & $1-3000$ & $1-200$ \\
\hline No. 5 & 1 C & $1-13$ & Mixed & $1-1000$ & $1-100$ \\
\hline No. 6 & 1C & $1-13$ & Girls & $1-2000$ & $1-100$ \\
\hline No. 7 & 1 C & $1-13$ & Girls & $1-2000$ & $1-100$ \\
\hline No. 8 & National & $1-13$ & Boys & $1-5000$ & $1-200$ \\
\hline No. 9 & 1 C & $1-13$ & Boys & $1-2000$ & $1-100$ \\
\hline No. 10 & 1 AB & $6-13$ & Mixed & $1-2000$ & $1-100$ \\
\hline
\end{tabular}

\subsection{Interview}

This case study involves the collection of data through semi-structured interviews with the principal of the selected school. According to Anderson (1998), the interview source has two advantages; interviews can be used for gathering depth of understanding of issues that are related to the case, and to identify key information that are part of the case. In addition, "Interviews may be either open-ended or guided" (Field et al., 1985, p. 65). According to Field's categorisation, open-ended interviews are suitable for this investigation. This is because the researcher needed to develop a better relationship in response to the data identified. "Data is typically collected through in-depth, open-ended interviews and that allow each person to fully describe their experience" (Reid \& Petocz, 2006, p. 6), while Pan Arab Research Centre (2009, p. 1) describes in-depth interviews as, "This method consists of interviewing and individual on a one-to-one basis. Typical interviewing approaches utilise an assortment of direct/indirect, structured/unstructured, distinguished/undistinguished questions, thus allowing the interviewer to read the respondents' attitudes, emotional reactions, opinions, etc, and the quality of the response by linking it with another subsequent questions".

The ten secondary school principals were invited to participate by telephone and discussions to set the location, date and time of the interview were held with the principals as well. All of the conversations during the interviews were tape recorded. During the interviews, the researcher planned the directions of the interview by developing another set of open-ended questions. The interview concluded in three to four hours. Hence, these interviews helped to gather information that includes the participants' thought, beliefs, knowledge, reasoning, motivations and feelings about the topic (Johnson \& Christensen, 2000). 


\subsection{Non-Participant Observation}

Data that were considered relevant to the study were collected by conducting non-participative observation which related to the SBTD program at the respective schools. During this observation, important instances, situations, activities, happenings were noted in the field book and photographed. Germain (1986) describes the role of observer in a research study. "In this role, the field worker may be visible but does not interact with those being observed, for example, in a meeting of a board of Directors, or as a "professional loiterer" (non-participative observation)", while, Silverman $(2007$, p. 37) states that, “...qualitative researcher can access fascinating data by observing".

\subsection{Document Searching}

Punch (2009, p. 158) mentions "Documents, both historical and contemporary, are rich sources of data for education and social research". Therefore these sources are used for this study. Punch further describes the importance of documentary data as some education research depends entirely on this type data. In some case studies, documentary data may be gathered in conjunction with interviews and observations. For this purpose, with other data documents, it would be used in triangulation.

\subsection{Data Analysis}

In this research the data analysis process, four codes have been developed and each code includes several sub-codes. "Any number of possible codes may be used and the coding categories become specific to the research study" (Wiersma \& Jurs, 2005, p. 207). Fleet and Cambourne (1989) discuss the coding of naturalistic data and they provide some steps of the coding process.

In this investigation, triangulation was used to develop the validity of the result. Rothe (2000, $\mathrm{p}$. 23) explains Triangulation as "search, by using several different bearings from different directions". In addition, triangulation seeks convergence, corroboration and correspondence of results from the different methods to increase the validity of constructs and inquiry results by counteracting or maximizing the heterogeneity of irrelevant sources of variance attributable especially to inherent method bias, but also to inquire bias, bias of substantive theory of inquiry context.

This study recognises the interactions of various factors both internal and external that influence the implementation of SBTD programs. The Activity Theory (AT) framework was selected to analyse the ecology surrounding the organisation and implementation of SBTD programs and NSBTD programs in the Sri Lankan cultural context.

\subsection{Ethical Consideration}

Bieger \& Gerlach's (1996, p. 227) advice to researchers is that "All research studies must be conducted in an ethical manner". In this investigation, ethical procedures in the conduct of research were followed. In this case study, ten principals were interviewed and throughout the interviews proper ethical conducts were observed and taken into consideration. 


\section{Results and Discussions}

According to the findings, Principals were not aware about the concepts of SBTD programs. When interviewing the principals, they mentioned that they needed awareness about all the professional development programs for teachers, especially the SBTD programs. This is because they complained that they were not trained to organise SBTD programs for their teachers. Further, one of the causes (among 10 cases) for the differences in the implementation of SBTD programs is that there were no guidance and training offered at the national level on how the principals should conduct the programs. Thus, they conducted the program based on their own knowledge and the specific needs of the teachers.

Schools did not have policy documents, circulars, or handbooks to provide guidelines to organise SBTD programs. The findings show three schools had their own policies and particular procedures of SBTD programs. These policies and procedures were made by the school principals alone or in correlation with the staff. These policies and procedures were different from school to school because of the lack of a government policy document as a guideline to principals regarding SBTD programs. The principals of this study pointed out that currently the SBTD concept is not popular. Some principals and teachers did not fully understand this concept as well as its importance. On the other hand SBTD programs need to be developed so that at the national level "SBTD programs day" would be named in a year. A suitable holiday or a weekend selected for this day at every school can organise various types of SBTD programs. Consequently, this SBTD concept will be popular and benefit teachers.

Some effective SBTD programs were found in this study. Some events of these programs were of a high standard and considered the basic principles of SBTD programs. The quality of SBTD programs depends on school principals. The coordination of these programs was poor. Some enthusiastic principals organise these programs without any coordination of the top-level personals.

Encouragement to development of SBTD programs was insufficient at Zonal levels. High quality events of SBTD program were not recognized by the Ministry of Education (MOE). Further, 60\% of the principals mentioned the lack of coordination of SBTD and NSBTD programs as one of the major problems in enhancing the teacher professional development program. It seems that this problem can be solved since the SBTD programs can be coordinating, organising and implementing at the individual school level. Another significant problem that relates to the lack of coordination of the NSBTD programs is that the seminars or workshops can become invalid because these programs are not accredited. Furthermore, many NSBTD programs frequently overlap with each other requiring integration and coordination of both NSBTD and SBTD programs. Both programs should be coordinated and integrated by an independent government organisation such as the National Authority of Teacher Education (NATE) in Sri Lanka.

Effective and innovative SBTD activities were identified in three schools. However, quality, occasions, amount of the activities were variable school by school. Further, Research findings showed that NSBTD programs did not consider individual teachers' and schools' needs. The focus was primarily to impart changes in the syllabuses, and reforms on the teacher professional 
development opportunities were ignored. The administration of NSBTD programs was traditional and hierarchical and unqualified personnel resources were used frequently. However, these programs have advantages and therefore they assist to develop teacher professionalism. NSBTD programs were organised by different institutions such as Ministry of Education (MOE), National Institute of Education (NIE), Provincial Ministry of Education (PMOE), Zonal Education Offices (ZEO), but there was no coordination among these programs. As a result some programs overlapped with each other.

The SBM concept was not implemented in Sri Lanka. Under SBM concept, the secondary school principals have power and authority to organise and implement SBTD programs.

A teacher evaluation procedure was not specifically outlined in the Sri Lankan education system. This resulted in different methods being used for teacher evaluation from time to consequently principals had difficulties in evaluating teachers. Further, principals suggested that SBTD programs be used to evaluate teachers in the workplace.

Induction programs for Newly Qualified Teachers (NQT) are very important, and these programs highly benefit them. The principals' suggestion is induction programs for NQT are based on individual schools.

The Sri Lankan education management system is hierarchical, and any decisions and orders follow the top-down process. This management style is well-established in the education system. Thus, the principals of the schools are used to following directives and orders from the higher authority. Principals always expect orders or opinion from the top level and they expect the top level to give them directions. However, good professional development programs are combined with top-down and bottom-up initiatives (Blackmore, 1999; Fullan, 1994). In this study, 70\% of the principals believed that to organise and implement SBTD programs, orders, policies, circulars, encouragement, supervision and feedback should come from the ZEO or top administration levels. The principals are not trained to make their own decisions. On the other hand, under the same circumstances, some principals organised and implemented sufficient SBTD opportunities for their teachers. In addition, the majority of principals demand the power and authority to organise and implement SBTD programs. The contradiction is that $30 \%$ of the principals have already provided SBTD programs to their teachers. Besides, under the concept of School-Based Management (SBM), they have had some degrees of this power and authority; however, this concept needs to be developed.

\section{Conclusions and Recommendations}

This research focused on the provision of SBTD programs in Sri Lankan secondary schools, focusing on factors that impede or facilitate the provision of such programs in Sri Lanka. The overall conclusion to this study, based on the data from the participating research sites, is that endemic systemic problems in and across the Sri Lankan Education system have left schools without national or local policy and professional development frameworks in regard to the provision of SBTD in Sri Lankan secondary schools. Due to the small sample size of schools included in this study (10 from approximately 10,000) - it is evident that this finding needs 
confirmation from a larger scale study in and across the nine provinces responsible for the provision of secondary education.

The study also identified that, in the absence of national or local policy frameworks, secondary school principals are the key facilitating and/or limiting factor in the development and offering of SBTD programs. In this study, only a minority of principals (30\%) facilitated the development of high quality SBTD programs. This finding also needs to be validated by a wider scale study.

It is recommended that top-level Education Officers should develop and implement a support program for principals in regard to developing and offering SBTD programs. The study also identified the small number of research studies conducted in the Sri Lankan context and recommends the commissioning of further case studies and policy analysis and development.

\section{References}

[1] AISV (2006). Principles of Effective Professional Learning. Association of Independent School of Victoria-AISA,

[2] Anderson, G. (1998). Fundamentals of Education Research.Philadelphia, Pennsylvania, Routledge Falmer, Tylor \& Francis Inc.

[3] Bieger, R. G. \& Gerlach, G. J. (1996). Educational Research A Practical Approach.London, International Thomson Publishing Europe Berkshire House

[4] Blackmore, J. (1999). 'So we have to do professional development as well now?' Teacher learning networks: professional activism and the pedagogies of discomfort aroud educational change,. Keynote to the Teacher Learning Network Deakin University, 1-34

[5] Blackmore, J. (2000). Developing conditions conductive to teacher professional renewal. Teacher Learning Network-Professional Development Issue, Vol, 7 No. 1 Summer

[6] Borg, W. R., Gall, J. P. \& Gall, M. D. (1993). Applying Educational Research.New York, Longman

[7] Clair, N. \& Adger, C. T. (1999). Professional Development for Teachers in Culturally Diverse Schools. http://www.cal.org/resources/profdvpt.html

[8] DETYA (2005). Professional Learning in Effective Schools. The Department of Education \& Training. Melbourne.

[9] Field, Morse, P.-A. a. \& Janice (1985). 'Interview techniques' from 'Methods of data collection'.pp,65-73.Aspen, Rockville,Maryland

[10] Fleet, A. \& Cambourne, B. (1989). 'The coding of naturalistic data'. Research in education, Number $41,1-15$

[11] Fullan, M. (1994). Coordinating Top-Down and Bottom-Up Strategies for Educational Reform. http://www.michaelfullan.ca/Articles_98-99/09_94.pdf

[12] Good, J., M, Weaver \& Andrew (2003). Creating learning communities to meet teachers' need in professional development. Journel of In-service Education, Volume 29 Number 3 pp. 439-450 (12)

[13] Germain, C. (1986). 'Ethnography: the method', In nursing research: a qualitative perspective.Norwalk, Connecticut, Appleton-Century-Crofts

[14] Johnson, B. \& Christensen, L. (2000). Educational Research.Needham Heights, Allyn \& Bacon

[15] Linda, D. (2005). Prepping Our Teachers for Teaching as a profession. Education Digest, Vol. 71, p $22-27$

[16] Mathews, B. (2002). Case study on the Secondary Education Development Project. Asian Development Bank. Colombo.I

[17] Margarita, C. (1997). Staff Development in Multilingual Multicultural Schools. ERIC/CUE Digest 124. ERIC. 
[18] Merritt, L. (2003). Embedding research as core practice for teachers: A model for whole schools teachers learning. University of Sydney. Sydney.PhD

[19] MOE (2004). The Development of Education: National Report. Ministry of Education, Sri Lanka Colombo.http://www.ibe.unesco.org//International/ICE47/Englishreports/Srilanka.pdf

[20] MOE (2005). Education for Economic Development and Prosperity. Ministry of Education, Sri Lanka. Colombo.

[21] Monyatsi, P. P. (2006). An investigation of the effectiveness of the school-based workshops approach to staff development in secondary schools in Botswana. Education Research and Reviews vol, 1 (5),pp, 150-155.http:/ www.acadamicjournals.org/ERR

[22] NSES (2008). Standards for Professional Development for Teachers of Science. National Science Education Standards. http://www.nap.edu/readingroom/books/nses/4.html

[23] Punch, K. F. (2009). Introduction to Research Methods in Education.London, SAGE Publications

[24] Reid, A. \& Petocz, p. (2006). Being Critical About Approaches To Research In Statistics Education. Macquarie University, Australia. http://www.stat.auckland.ac.nz/ iase/publications/17/6f1-REID.pdf

[25] Rothe, P. J. (2000). Understanding Qualitative Research.Albera, Canada Council for the Arts

[26] Sethunga, P. (2007). The Study on School Based Teacher Development Programmes. Department of Education, Faculty of Arts, University of Peradeniya. Peradeniya.

[27] Sethunga, P. \& Devananda, S. (2007). A study on school based teacher development progammes in Sri Lanka. Department of Education, University of Peradeniya. Peradeniya, Sri Lanka.

[28] Silverman, D. (2007). A Very Short, Fairly Interesting and Reasonably Cheap Book about Qualitative research.London, SAGE Publications Ltd

[29] Wickramasinghe, Y. (2002). Staff Development Programmes in Sri Lankan Schools. National Institute of Education, Sri lanka. Padukka.MSc

[30] Wiersma, W. \& Jurs, S. G. (2005). Research Methods In Education an introduction.Boston, Allyn \& Bacon

[31] Zammit, K., Sinclair, C., Cole, B., Singh, M., Costley, D., a'Court, L. B. \& Rushton, K. (2007). Teaching and leading for quality Australian schools: A review and synthesis of research-based knowledge.Tharwa NSW, University of Western Sydney

*Corresponding author.

E-mail address: bandarabms@ gmail.com 